\title{
When Anti-Aging Studies Meet Cancer Chemoprevention: Can Anti-Aging Agent Kill Two Birds with One Blow?
}

\author{
Noriko N. Yokoyama ${ }^{1}$ Andria P. Denmon ${ }^{1} \cdot$ Edward M. Uchio $^{1}$. \\ Mark Jordan $^{1} \cdot$ Dan Mercola ${ }^{2} \cdot$ Xiaolin $\mathrm{Zi}^{1,3,4}$
}

Published online: 14 April 2015

(C) Springer International Publishing AG 2015

\begin{abstract}
Recent evidence has strongly supported that the rate of aging is controlled, at least to some extent, by evolutionarily conserved nutrient-sensing pathways (e.g., the insulin/insulin growth factor 1 (IGF-1)-signaling, molecular target of rapamycin in mammals (mTOR), adenosine monophosphate-activated protein kinase (AMPK), and sirtuins) from worms to humans. These pathways are also commonly involved in carcinogenesis and cancer metabolism. Agents (e.g., metformin, resveratrol, and Rhodiola) that target these nutrient-sensing pathways often have both anti-aging and anti-cancer efficacy. These agents not only reprogram energy metabolism of malignant cells, but also target normal postmitotic cells by suppressing their conversion into senescent cells, which confers systematic metabolism benefits. These agents are fundamentally different from chemotherapy (e.g., paclitaxel and doxorubicin) or radiation therapy that causes molecular damage (e.g., DNA and protein damages) and thereby no selection resistance may be expected. By reviewing molecular mechanisms of action, epidemiological evidence, experimental data in tumor models, and early clinical study results, this review provides information supporting
\end{abstract}

This article is part of the Topical Collection on Cancer Chemoprevention

Xiaolin Zi

xzi@uci.edu

1 Departments of Urology, University of California, Irvine, 101 The City Drive South, Rt.81 Bldg.55 Rm.302, Orange, CA 92868, USA

2 Departments of Pathology and Laboratory Medicine, University of California, Irvine, Orange, CA 92868, USA

3 Departments of Pharmacology, University of California, Irvine, Orange, CA 92868, USA

4 Chao Family Comprehensive Cancer Center, University of California, Irvine, Orange, CA 92868, USA the promising use of agents with both anti-aging and anticancer efficacy for cancer chemoprevention.

Keywords Chemoprevention · Aging $\cdot$ Nutrient-sensing signaling pathways $\cdot$ Cancer

\section{Introduction}

Aging is a major risk factor for many common cancers, such as bladder, prostate, kidney, lung, colon, and breast cancers [1]. The risk of cancer of those 55 or older increases up to 78 and $58 \%$ in first- and third-world countries, respectively [1]. Due to the dramatically increased life expectancy in the twenty-first century, cancer has become a major health and economic burden in many countries. In the USA, approximately 1.6 million people are diagnosed with cancer and one out of four elderly people die from cancer each year [1]. As populations continue aging, the global cancer burden is expected to increase $50 \%$ by 2020 [2].

Proposed hallmarks of aging include deregulated nutrientsensing, genomic instability, telomere shortening, mitochondrial dysfunction, cellular senescence, aberrant epigenetic alterations, imbalance of protein homeostasis, loss of proteostasis, stem cell exhaustion, altered inter-cellular and intracellular communications, and inflammation [3]. Notably, all of these hallmarks of aging are also observed during the process of carcinogenesis, suggesting that cancer and aging are both associated at the molecular level. However, the molecular link between aging and the development of cancer, in particular how aging leads to carcinogenesis, remains largely unknown. The current paradigm is that aging and cancer are driven by the accumulation of molecular damage, such as DNA damage $[4,5]$. This paradigm has recently been challenged by accumulating evidence demonstrating that 
evolutionarily conserved nutrient-sensing pathways (e.g., insulin/insulin growth factor 1 (IGF-1), molecular target of rapamycin in mammals (mTOR), adenosine monophosphate-activated protein kinase (AMPK), and sirtuins) are, at least to some extent, required for overall life span and healthy aging across different species from worms to humans $[3,6]$. Nutrient-excessive conditions activate the insulin/IGF-1 and mTOR pathways, whereas, nutrient restriction activates the AMPK and sirtuin pathways (Fig. 1) [3, 6, 7]. Altering nutrient-sensing pathways by either inhibiting the insulin/IGF-1 and the mTOR pathway or activating the AMPK and sirtuins pathways lead to the longevity of an organism $[3,6]$. Anti-aging studies have shown that these nutrient-sensing pathways can be modulated by nutritional approach [e.g., calorie restriction (CR)] [8], a preventive drug (e.g., metformin and aspirin) [9, 10], and dietary supplements (e.g., resveratrol and Rhodiola) [11-14]. Importantly, these nutrient-sensing pathways are also involved in cancer development and progression [15-18]. Therefore, interventions that target nutrient-sensing pathways for slowing down aging may also reduce and delay the process of carcinogenesis and prevent cancer.

Current efforts to treat cancer include radiotherapy, chemotherapy, and surgery. However, many elderly cancer patients are not tolerant of these treatments, which decrease their quality of life $[19,20]$. Chemoprevention is an approach to delay the process of carcinogenesis by the use of natural, synthetic, or biological agents in order to reduce cancer incidence, morbidity, and mortality, as well as to improve overall quality of life [21]. The high incidence of many cancers in aging populations suggests that cancer is an age-related disease, and agents that inhibit or delay cancer development and progression in the elderly could yield significant reductions in cancer morbidity and mortality $[19,20]$. Therefore, non-toxic or less toxic agents (e.g., metformin, resveratrol, aspirin, and Rhodiola) with anti-aging properties are suitable for cancer chemoprevention in the elderly.

In this review, we have attempted to summarize the role of the most common nutrient-sensing pathways at the intersection of aging and cancer (Fig. 1), as well as mechanisms by which anti-aging agents could slow down aging and inhibit carcinogenesis.

\section{Nutrient-Sensing Pathways at the Intersection of Aging and Cancer}

\section{The Insulin and IGF-1 Signaling Pathway}

The insulin and IGF-1 signaling pathway is an evolutionarily conserved nutrient-sensing and bioenergetic pathway with a major impact on longevity $[22,23]$. Constitutively decreased insulin- and IGF-1 signaling can extend the life span of model

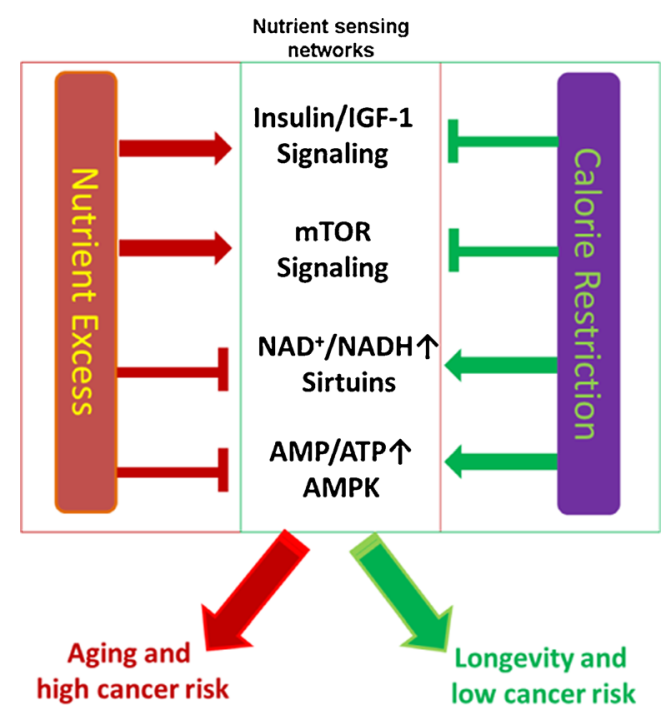

Fig. 1 The effect of nutrient excess and caloric restrictive conditions on longevity and cancer risk via nutrient-sensing signaling networks. Nutrient excessive conditions activate insulin/IGF-1 and the mTOR pathways for promoting aging and cancer risk, whereas, nutrient restrictive conditions activate AMPK and sirtuins pathways for increasing longevity and reducing cancer risk

organisms, such as yeast, worms, fruit flies, and mice [24-27]. On the contrary, studies also showed that supplementation of IGF-1 can improve premature aging in progeroid mice, which have low levels of IGF-1. These results suggest that there may be an important balance in expression of IGF-1 for longevity [28]. The role of insulin and IGF-1 signaling in human aging is also controversial and contradicts animal studies. Some studies reported reduced longevity of patients with growth hormone deficiency $[29,30]$. For example, individuals with growth hormone $(\mathrm{GH})$-resistance dwarfism have a reduced life span [30]. Other studies reported that lower levels of IGF-1 was not a good predictor for longevity; however, lower levels of IGF-1 in cancer patients predicted longer survival $[31,32 \cdot]$. Currently, it remains debatable and largely unknown about the long-term effects of IGF-1 on human aging [24, 33].

Although gene amplification and activating mutations of insulin and IGF-1 receptor family members are not common in cancer, abnormal autocrine or paracrine expression of ligands are common [14]. IGF-1 and IGF-2, which are secreted by mammary adipose tissues, have been shown to have significant paracrine effects and contribute to diabetes associated cancer [34]. Evidences from epidemiological studies have demonstrated that high circulating IGF-1 levels are associated with an increased risk for gastrointestinal, prostate, breast, colorectal, and ovarian cancers and negatively affect cancer prognosis [14, 35-38]. Earlier studies examining the IGF-1 receptor in fibroblast cells showed that it was required for the transforming activity of simian virus 40 large tumor antigen (SV40T) [39]. To characterize the role of IGF-1 in carcinogenesis, Hursting SD et al. [40] generated transgenic mice overexpressing human IGF-1. When the carcinogen, p- 
cresidine, was introduced, these transgenic mice exhibited greatly increased bladder tumors compared to nontransgenic mice. In addition, insulin secretion rate as indicated by cpeptide levels influenced cancer risk [41, 42]. Patients with congenital deficiencies in IGF-1 and growth hormone are resistant to cancer and aging development [29]. Taken together, the above results suggest that the modulation of insulin and IGF-1 levels in tissues or the circulation in the body would be promising for both anti-aging and cancer prevention.

\section{The mTOR Pathway}

mTOR is a conserved serine/threonine kinase that belongs to the phosphoinostitide-3-kinase (PI3K)-related kinase family and consists of two multiprotein complexes, mTORC1 and mTORC2 [18]. mTOR plays a key role in energy management at both the cellular and organismal level by getting cues from cellular nutrients, oxygen, and energy [18]. There have been many reports of the mTOR pathway promoting aging in different model organisms. Inhibition of mTORC1 activity by genetic approaches can extend the life span of yeast, worms, and flies [43-48]. Mice with genetically modified low levels of mTORC1 activity or deficient in its downstream target S6K1, but with normal levels of mTORC2 activity exhibit extended life spans [49]. Rapamycin, a specific inhibitor of mTORC 1 normally used to treat various cancers, has been shown to enhance the longevity of mice by 9 to $14 \%[47$, 48]. Rapamycin can also delay the onset or progression of multiple age-related phenotypes, such as tendon stiffening, liver deterioration, and cardiac dysfunction to name a few [50]. Recently, a clinical trial of rapamycin at half the dose that a kidney transplant patient would receive for slowing aging has been carried out in five men at their late $80 \mathrm{~s}$ and 90s [51]. Initial results from this trial have shown that men receiving rapamycin have increased walking ability and responsiveness to the hepatitis B vaccine compared to the controls [51]. Therefore, rapamycin which decreases mTORC1 seems to slow down cellular senescence and aging of an already elderly population.

The PI3K/AKT/mTOR pathway is commonly activated in many cancer and tumor syndromes. It has been estimated that mTORC 1 is aberrantly activated in up to $80 \%$ of human cancers [52]. The mTOR pathway can be activated by mutations in the PI3K, mTOR, or AKT genes; loss of PTEN, NF-1, PIK3CA, VHL, TSC2, or TSC1; or constitutive activation of Ras, Src, Raf, or MEK [53-55]. During the process of carcinogenesis, multiple rounds of cellular proliferation and selection can transform initially random mutations into nonrandom activation of the mTOR pathway [53]. Given the oncogenic properties of this pathway, many agents that inhibit the PI3K/AKT/mTOR pathway at different levels, such as mTOR inhibitors, pure PI3K inhibitors, dual PI3K-mTOR inhibitors, and AKT inhibitors are in clinical development
$[56,57]$. Several mTOR inhibitors, rapamycin analogs including everolimus and temsirolimus, have shown benefits of overall survival in large clinical trials against angiomyolipoma associated with tuberous sclerosis, metastatic renal cell carcinoma, breast cancer, and pancreatic neuroendocrine carcinomas $[58,59]$. The PI3K/AKT/mTOR pathway is also recognized to play a central role in tobacco smoking-induced carcinogenesis, and inhibitors of this pathway, including myoinositol and metformin, are promising agents for lung cancer prevention [60].

Although inhibition of mTOR activity seems to have beneficial effects for anti-aging, cancer prevention, and treatment, adverse events observed in patients treated with mTOR inhibitors (e.g., rapamycin) are fairly common, regardless of each specific indication. These undesirable side effects include stomatitis, skin rash, and non-infectious pneumonitis, as well as elevated blood glucose, cholesterol, and triglyceride levels leading to the development of insulin resistance and increased incidence of infections [61, 62]. Therefore, there is a need for the development of non-toxic mTOR inhibitors for the purpose of cancer chemoprevention for long-term use.

\section{AMPK Pathway}

In contrast to the insulin and IGF-1 signaling and mTOR pathways that detect nutrient abundance and anabolism, AMPK and sirtuins are two nutrient sensors that are activated by the increase in cellular AMP and NAD + concentrations, respectively, in response to nutrient scarcity and catabolism [63]. Accordingly, the upregulation of AMPK and sirtuins promote healthy aging.

There are many studies with lower organisms (e.g., worms, fruit flies, and rodents) linking increased AMPK signaling to longevity. Overexpression of AAK-2 (catalytic subunits of AMPK in Caenorhabditis elegans) increases life span by $13 \%$ and mimics dietary restriction in well-fed animals [64]. Similar increases in the life span of the fruit fly are also seen in overexpression of the single Drosophila AMPK- $\alpha$ subunit in either muscle or the fat body [65]. Additionally, AMPK upstream activator such as liver kinase B1 (LKB1), and its downstream effecters, cAMP-responsive element-binding protein (CREB)-regulated transcriptional coactivators (CRTCs), UNC-51-like kinase 1(ULK1), mTOR, FOXO, and sirtuins have been shown to be involved in life span extension [66-69]. In recent studies, pharmacological agents that directly activate AMPK, such as aspirin and its metabolite salicylate, as well as A-769662 and C24, resulted in similar life extension effects as do AMPK indirect activators (e.g., metformin, dietary restriction, and resveratrol) $[10,70,71 \bullet$, 72, 73]. Therefore, these results indicated that AMPK has potent ability to modulate life span and it is an ideal target for promoting healthy longevity. 
Due to AMPK's important role in maintaining energy balance, perturbation or decreased AMPK activation may be associated with increased cancer risk in human metabolic disorders, such as obesity, diabetes, and the metabolic syndrome. Activation of AMPK by CR and metformin has been considered to be one of the main mechanisms for their cancer prevention benefit in patients with these metabolic disorders [74]. In addition, LKB1 (an upstream activator of AMPK) mutations commonly occur in sporadic non-small cell lung carcinoma [75] and are associated with the greatly increased cancer risk in the inherited Peutz-Jeghers syndrome [76]. In mouse studies, loss of function of LKB1 resulted in increased susceptibility to cancer development [77]. These findings have led to more studies on pharmacological activators of AMPK.

In some studies, AMPK $\alpha, \beta$, and $\gamma$ subunits were also found to be overexpressed in 2 to $25 \%$ of human cancers and cancer cell lines. Therefore, AMPK activation can also promote cancer growth and survival under certain conditions by supporting the metabolic changes needed for tumor growth $[17,78-80]$. Thus, approaches of targeting AMPK activation or inhibition for cancer therapy requires further investigation for their context dependent effects and cautious evaluation needs to be done.

\section{Sirtuins}

Silent information regulator 2 (Sir2) homologues, named "sirtuins", function to catalyze NAD+-dependent protein deacylation and mono-ADP ribosylation reactions [81]. Sir2 homologues increased the life span and protected against agerelated pathologies in nematode worms and fruit fly experimental systems as well as in specific yeast strains and mice [81]. There are seven mammalian sirtuins (SIRT1-7). These sirtuins are differentially located in the cells and have different functions and biochemical activities. SIRT1 shares the most homology with the founding member of yeast Sir2 and is located in the nucleus. SIRT1 overexpression has been shown to delay the onset of many age-related diseases, such as cardiac hypertrophy and neuropathies [82, 83]. SIRT2 is primarily localized in the cytoplasm, but can translocate into the nucleus during the G2M phase of the cell cycle [81]. SIRTs 3,4 , and 5 localize to the mitochondria [81]. Among the mitochondrial sirtuins, SIRT3 protects against the accumulation of oxidative damage and attenuates age-associated hearing, suggesting its strong association with aging [84, 85]. SIRT6 is expressed in the nucleus and also known to be associated with aging. SIRT6 knockout mice have severely shortened life span, while overexpression of SIRT6 extended their life spans [86•]. Moreover, SIRT6 seems to protect against many age-related pathologies, both at the cellular and the systematic level. For example, aging and failing hearts express lower levels of SIRT6, and SIRT6 knockout mice displayed cardiac hypertrophy and heart failure [87]. Interestingly,
SIRT6 overexpression in cardiomyocytes inhibited AKTIGF signaling and protected against cardiac hypertrophy [88]. Accumulating evidence shows that SIRT6 plays a central role in regulating longevity-related pathways.

Activation of sirtuins appears to be a key mechanism for several anti-aging approaches [89]. Mild caloric restriction and decreased glucose consumption, as well as resveratrol and synthetic sirtuin-activating compounds (STACs) have been used to activate sirtuins because of their effects on modulation of aging and age-related disease in mammals [89].

Sirtuins play a role in proliferation, apoptosis, DNA repair, metabolism, and inflammation under basal or stress conditions [90]. Sirtuins also play a significant role in tumorigenesis. During tumorigenesis, sirtuins function both as a tumor promoter and a tumor suppressor, depending on the cellular context or tumor type. SIRT2 is downregulated in gliomas, breast cancer, head and neck squamous cell carcinoma, and esophagus adenocarcinoma [91-94]. SIRT2 knockout mice develop liver cancer and mammary gland tumors [95]. SIRT3 is downregulated in breast cancer, hepatocellular carcinoma (HCC), and head and neck squamous cell carcinoma [96]. Knockout mice of SIRT3 develop mammary gland tumors [97]. SIRT4 regulates glutamine metabolism and is downregulated in lung cancer [98]. The SIRT6 chromosomal locus was found to be deleted in pancreatic, colon, and liver cancers $[99,100]$. Loss of SIRT6 expression resulted in tumor formation by increasing glycolysis [100]. In contrast, there are few reports where sirtuins were overexpressed and promoted cancer. SIRT6 is reported to be overexpressed in pancreatic cancer cells and associated with chemoresistance by increasing inflammation and angiogenesis signaling [101]. SIRT2 is upregulated in acute myeloid leukemia, neuroblastoma, pancreatic cancer, HCC, and regulates the Myc oncogenic pathway [102].

Sirtuins appear to play a complex and diverse role in both aging and cancers. Further studies are needed to define the exact molecular mechanisms by which each sirtuin member functions in a particular cell or organ to affect tumor development. Elucidating the mechanism of sirtuin function would help identify a potential link between aging and cancer and eventually develop cancer chemopreventive agents against age-related cancers.

\section{Approaches or Agents with both Anti-Aging and Anti-Cancer Effects}

\section{Caloric Restriction}

Long-term CR without malnutrition is the most robust interventions known to increase maximal life span and health span in many organisms [24, 103-106]. Studies in yeast, rotifers, nematode worms, fruit flies, rodents, and non-human primates have demonstrated that reduction of calories 30 to $50 \%$ below 
ad libitum levels of a nutritious diet can increase life span [24, 103-106]. In non-human and human primate studies, CR without malnutrition protects against abdominal obesity, diabetes, hypertension, and cardiovascular diseases [106]. However, whether CR can slow human aging remains to be determined and human trials for evaluating $\mathrm{CR}$ are ongoing. The early results of CR trials from several published studies [107-109] reported that participants could only reduce caloric intake by 10 to $14 \%$ for a period of 6 to 12 months, even with the highly motivated volunteers assisted by the most up-todate support and information, which is far lower than the lifetime restriction of 30 to $50 \%$ associated with anti-aging effects in laboratory animals such as rodents and non-human primates. Therefore, these results suggest that application of $\mathrm{CR}$ in humans for anti-aging would not be practical due to the degree and length of restriction required. In addition, it is harder to control the degree and time of CR onset and the timing of food intake as well as diet composition in human subjects, although these factors are important in promoting longevity and a healthy life span [8]. The high quality diets consumed by the CR practitioners may have beneficial effects on their metabolic health; however, it may not be entirely dependent on the calorie intake [8]. Therefore, it is important to understand molecular mechanisms of CR's anti-aging effect and develop interventions that would mimic the effect of CR without the difficulties of severely reducing nutrient intake.

Multiple mechanisms have been shown to mediate CR longevity. CR consistently reduces IGF-1 concentration by up to $40 \%$ via the growth hormone (GH)/IGF-1 axis in mice [110, 111]. CR also decreases mTOR activity and mTOR inhibition by both genetic and pharmacological approaches, which phenocopies CR, thus increasing life span [112]. In addition, other factors, including DAF-16 (FOXO), SKN-1(Nrf1/2/3), PHA-4 (FOXA), and AAK-2 (AMPK), that are involved in stress responses and mTOR signaling also play a role in $\mathrm{CR}$ mediated longevity [113]. CR also activates sirtuins and increases NAD + by shifting toward oxidative metabolism rather than increasing total respiration. SIRT1 and the nicotinamidase PNC-1, a key NAD+ salvage pathway component, are largely required for diet restriction to increase life span [113].

People who undergo long-term CR show a reduction of metabolic and hormonal factors associated with increased cancer risk $[114,115]$. Studies over the years have shown that laboratory animals receiving a CR diet had a significantly lower risk of getting tumors compared to animals supplemented with a regular diet. For example, cancer morbidity and mortality significantly decreased in CR monkeys $[114,115]$. CR has been shown to inhibit the growth of transplantable, spontaneous, radiation, and chemically induced tumors in mouse models [114-117]. One study showed that CR inhibited p-cresidine-induced bladder carcinogenesis in heterozygous $\mathrm{p} 53$-deficient mice via reduction of circulating
IGF-1 levels [117]. However, the protective effect of CR on bladder carcinogenesis was reversed by restoring serum IGF-1 levels via the administration of exogenous human IGF-1 [117]. In addition, mTOR activity can be inhibited by CR and MTOR inhibitors have emerged to mimic CR for delaying cancer development in mice [112]. These results suggest that the inhibition of IGF-1 and mTOR signaling and CR might share similar or overlapping mechanisms for both life span extension and anti-cancer.

\section{Metformin}

Metformin is an antidiabetic drug, however, it appears to have various health benefits besides treating type 2 diabetes. In recent studies, metformin treatment increased life span in model organisms. Metformin increased the mean life span of Caenorhabditis elegans in a dose-dependent manner via peroxiredoxin PRDX-2 mediated mitohormesis and by altering microbial folate and methionine metabolism $[118,119]$. Metformin also increased the life span of mice with different genetic backgrounds and with specific diseases [120]. In R6/2 mice, which develop Huntington's disease, metformin increased the life span of male mice, but not the female mice [121]. Metformin also increased the life span of the transgenic HER-2/neu mice which develop mammary carcinomas [122]. In humans, metformin is associated with the reduction of allcause mortality and increased life expectancy in diabetic patients [123]. Metformin also reduced cardiovascular mortality in type 2 diabetes patients [123]. These results suggest that metfomin may act through both the basic mechanisms of aging and reduction of disease specific mortality to increase longevity in animals.

Epidemiological studies have shown that patients with type 2 diabetes are associated with about twofold or more risk for liver, pancreas, and endometrium cancers and 1.2-1.5-fold risk for rectum, breast, and bladder cancers [124-128]. Other cancers, such as lung cancer, appear not to be associated with type 2 diabetes, and prostate cancer may be detected less frequently in diabetic patients [124-128]. Epidemiological studies have also shown that metformin is associated with reducing cancer risk and/or increasing survival in diabetic patients compared to those diabetic patients who use other therapies [123]. It was estimated that the use of metformin in diabetic patients is associated with an approximately $30 \%$ reduction in the lifetime risk of cancer [123, 129•]. The survival benefit of metformin is tumor type specific. Metformin appears to be more effective in increasing the survival of colon and ovarian cancer patients with type 2 diabetes [130,131], whereas, the survival benefit of metformin is not fully confirmed yet for prostate and breast cancers with type 2 diabetes [132, 133].

However, whether metformin is also beneficial for patients without diabetes or for reducing cancer risk in general populations remains unknown. As metformin is well tolerated and 
inexpensive, with a high long-term safety profile, there are currently more than 100 clinical trials of metformin to address this question for cancer in different organs [134]. At least one phase II trial showed that metformin at different doses significantly decreased the level of insulin, testosterone, and other metabolic parameters associated with breast cancer prognosis in post-menopausal breast cancer patients without insulin resistance and with normal baseline insulin serum levels [135]. Hosono et al. [136] also showed that intake of $250 \mathrm{mg}$ /day metformin for 1 month inhibited both colorectal epithelial proliferation and aberrant crypt formation in a pilot randomized trial in nondiabetic patients. Furthermore, evidence from a wide spectrum of preclinical tumor models, including xenografts, chemically induced carcinogenesis, and spontaneous transgenic cancer models have also strongly supported the anti-tumor growth effects of metformin [137-139]. These results suggested that metformin deserves further clinical investigation for its cancer prevention benefits in nondiabetic patients and in general populations.

Molecular mechanisms for the antineoplastic activity of metformin include systemic effects on host metabolism and direct effects on cancer cells [16]. Systematically, metformin inhibits hepatic glucose production, increases insulin sensitivity, and reduces lipolysis in adipocytes and glucose absorption from intestines, which leads to reduced circulating insulin levels and decreased insulin/IGF-1 receptor-mediated activation of the PI3K pathway [16]. The mitochondria respiratory complex I is the central target responsible for metformin's effects [140]. The suppression of the mitochondrial respiratory chain by metformin results in a cellular ATP deficit and the activation of AMP, which in turn inhibits gluconeogenesis to lower blood glucose and subsequently reduces hyperinsulinemia [16, 140]. Additionally, metformin can selectively eliminate cancer stem cells (CSC) and increase the expression of micro (mi)RNA lethal-7 (let-7) and miR-200, which inhibits the epithelial-to-mesenchymal transition (EMT) [141-143]. Metformin also activates intracellular DNA damage response checkpoints and attenuates the antisenescence effects of the enhanced glycolysis of the Warburg effect $[144,145]$. Metformin is taken up by the cell surface organic cation transporter 1 (OCT1) [146]. The expression of OCT1 in specific tissues affects whether the drug achieves the pharmacologically relevant concentrations in tissues other than the liver.

\section{Resveratrol}

Resveratrol is a stilbenoid present in berries, grapes, peanuts, and wine. Consumption of resveratrol in red wine in some areas of France is associated with the reduced mortality from coronary heart disease despite the consumption of a high-fat diet [147]. Some studies have reported that resveratrol increased longevity in yeast, worms, fruit flies, and short-lived fish, as well as mice given a high-fat diet [148-151], whereas others also showed that resveratrol had no effect on life span [152-154]. Resveratrol was found to be the most potent SIRT1 activator in a screening assay [148]. Resveratrol is a potent $\mathrm{CR}$ mimetic agent and resveratrol at its long-term use overlaps the effect of long-term $\mathrm{CR}$ on adipose tissues and shares similar gene expression patterns with $\mathrm{CR}$ in mice [154]. In addition, resveratrol increased the metabolic rate and fasting body temperature in mice under a high-fat diet and exerted antidiabetic effects in mice $[155,156 \bullet \bullet]$. In human studies, resveratrol consumption improved cardiovascular function, insulin sensitivity, and $\mathrm{HbAlc}$ measurements as well as reduced inflammation with preexisting metabolic disease $[155,156 \bullet \cdot]$. Studies have reported that dietary intake of resveratrol by mice protected against many of the deleterious effects of high-fat diets and provided additional health benefits $[155,156 \bullet \bullet, 157,158]$.

Numerous preclinical studies have been carried out to investigate the cancer preventative and therapeutic effect of resveratrol in a wide variety of animal models, including tumor xenograft models, chemically induced carcinogenesis models, and transgenic spontaneous cancer models [164, 165]. Mixed results have been generated from these studies. In general, resveratrol is ineffective in treating preexisting tumors, whereas, resveratrol seem to be a promising cancer preventive agent for inhibiting tumor initiation, promotion, and progression $[159,160]$. Limited clinical trials of resveratrol in cancer with small sample sizes also suggest that resveratrol may serve as preventive agent rather than a therapeutic agent for treating cancer [161]. For example, one phase I clinical trial reported that resveratrol and grape powder administration only inhibited the expression of Wnt target genes in normal mucosa, but not in cancerous mucosa [161]. The bioavailability of resveratrol is a critical issue for its use as a cancer preventive agent. The reported peak plasma concentrations of resveratrol are about 2-4 $\mu \mathrm{M}$ [162]. However, it is also important to know whether resveratrol can reach to the bioactive levels in target organs where it may have the strongest preventive potential.

The anti-aging and anti-cancer mechanisms of resveratrol's actions are mainly mediated by inhibition of cAMP phosphodiesterases (PDEs), particularly PDE4, which leads to activation of AMPK/SIRT2 axis signaling, as well as expression of p21 and p27 for cell growth inhibition [156••]. Other potential resveratrol targets such as cyclooxygenases 1 and 2 have also been reported $[163,164]$.

\section{Aspirin/Salicylate}

Aspirin is an over the counter nonsteroidal, anti-inflammatory drug (NSAID) for treating pain and inflammation. Aspirin has been shown to extend the life span of Caenorhabditis elegans via AMPK and FOXO transcriptional factor-dependent 
manners [165]. Aspirin is rapidly metabolized to salicylate, which binds to AMPK $\beta 1$ and directly activate AMPK thereby increasing longevity of organisms [10]. Aspirin also inhibits oxidant stress and reduces age-associated functional declines and diseases [166]. Finally, aspirin also improves glucose metabolism, decreases fatty acid levels, and reduces all-cause mortality in patients with type 2 diabetes by likely activating AMPK signaling [166].

Substantial evidence has been generated from observational studies indicating that aspirin can protect against cardiovascular events and reduce incidence and mortality in a wide variety of cancers, including colorectal, oesophageal, gastric, breast, prostate, and lung cancers [167]. However, aspirin use is also associated with deleterious effects, such as gastrointestinal bleeding and hemorrhagic stroke [167]. For individuals 70 and older, aspirin associated gastrointestinal bleeding is minimal and the duration of aspirin use for reducing cancer risk requires no less than 5 years $[168,169]$. A recent, large population study indicated that prophylactic and daily use of aspirin in the general population 50-70 years old for a minimum of 5 years resulted in a net overall benefit, which outweighed the potential harms [168]. A randomized clinical trial of a daily $100-\mathrm{mg}$ aspirin tablet or a matching placebo for 5 years in 19,000 older healthy individuals (Aspirin in Reducing Events in the Elderly, or ASPREE) has also been initiated to determine the risks and benefits of a daily aspirin dose and its potential for cancer prevention in this elderly population [168].

\section{Rhodiola rosea $L$}

Rhodiola rosea $L$ is a perennial herbaceous plant of the Crassulaceae family that is widely distributed at high altitudes (up to $2280 \mathrm{~m}$ ) in the arctic and mountainous regions throughout Europe, Asia, and North America [169]. R. rosea has been used for centuries to enhance both the physical and mental performance in healthy populations [170]. Swedish herbal Rhodiola-5 (SHR-5) is a standardized $R$. rosea extract used as a nutrient supplement that the Swedish Herbal Institute (SHI) has been manufacturing since 1985 [171]. SHR-5 increased the mean and maximum life span of the fruit fly up to 24 and $31 \%$, respectively [172]. $R$. rosea extracts also extended the life span of yeast and worms, and delayed the agerelated decline of physical activity and increased stress resistance $[11,12,172]$. The effect of $R$. rosea extracts on life span has been shown to be independent of CR-related signaling pathways, including SIR2 proteins, insulin, and insulin-like growth factor signaling, and the TOR in fruit flies [12], but dependent on diet composition (in particular protein-tocarbohydrate ratios or sucrose contents) and expression of Msn2/Msn4 and Yap1 regulatory proteins [14].

In human urinary bladder cancer cells, SHR-5 induced autophagic cell death via inhibition of the mTOR pathways
[173•]. We have recently demonstrated a marked chemopreventive efficacy of SHR-5 in the UPII mutant Ha-ras bladder cancer transgenic model: approximately $95 \%$ of transgenic mice, which drank $1.25 \mathrm{mg} / \mathrm{ml}$ of SHR-5 containing water daily, survived over 6 months of age, versus $33.3 \%$ of mice, which drank normal water $(p<0.0001)$; Additionally, SHR-5 exposure reduced tumor bearing bladder weight by $67 \%$ [174]. Anecdotal evidence from a study involving 12 patients with superficial bladder cancer showed that $R$. rosea extracts decreased the median recurrence rate by $50 \%$ [175]. Salidroside is the main bioactive compound in $R$. rosea extracts. Salidroside prevented the loss of hematopoietic stem cells in mice under oxidative stress via activating DNA repair enzyme poly (ADP-ribose) polymerase-1 (PARP-1) activity [176]. Salidroside also inhibited cancer cell migration and invasion, as well as xenograft tumor growth of human glioma cells in nude mice $[177,178]$. Studies also showed that Rhodiola improved chemotherapy drug-induced toxicities in cancer patients, such as oral mucositis [179]. Thus, these results suggest that Rhodiola is a novel anti-aging herb with great promise for cancer chemoprevention.

\section{Lithocholic Acid and L-theanine}

Lithocholic acid (LCA) is a cholesterol-derived bioactive lipid that was identified as a potent, anti-aging, natural compound in a high-throughput screening assay for extending yeast longevity [180]. LCA delayed chronological aging in yeast by causing an age-related remodeling of glycerophospholipid synthesis leading to substantial changes in mitochondrial membrane lipidome and by altering the age-related chronology of mitochondrial respiration [181•].

LCA has also demonstrated broad growth inhibitory effects on cancer cell lines derived from different organ sites via induction of apoptosis. The mechanisms of LCA-induced apoptosis involved both extrinsic (death receptor) and intrinsic (mitochondrial) apoptosis pathways by engagement of plasma membrane-bound protein TGR5 (G protein-coupled bile acid receptor 1) on the cell surface, leading to activation of caspase 1,8 , and 9 mediated apoptosis cascades [182, 183]. LCA also showed the in vivo anti-cancer efficacy in xenograft models [184]. However, in carcinogenesis models, LCA acted either as a tumor suppressor or promoter [185]. The anticarcinogenic effect of LCA remains debatable.

L-theanine ( $\gamma$-glutamylethylamide) is a unique amino acid that was identified in green tea (Camellia sinensis) and in some mushrooms [186]. L-theanine extends the life span of worms, but has no effect on fruit flies [187]. L-theanine also demonstrated its anti-cancer effect by inhibiting growth of cancer cells both in in vitro cell culture system and in vivo xenograft models [188, 189]. L-theanine works by inhibiting glutamate transportation leading to a decrease of intracellular glutathione (GSH) [190, 191]. L-theanine appears to improve 


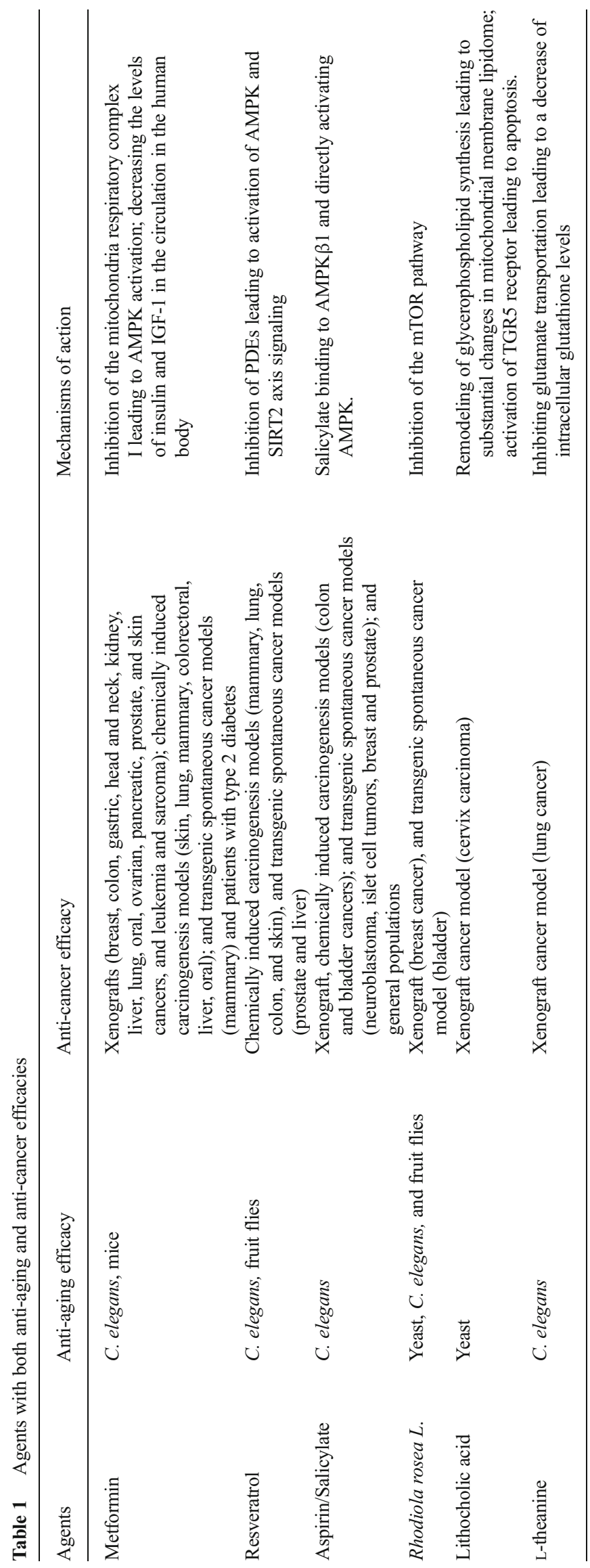


the efficacy of chemotherapeutic agents as well by increasing their accumulation in the tumor cells [190, 191]. L-theanine was also shown to protect normal cells from damage caused by chemotherapeutic agents via its antioxidant activity [190, 191]. Further studies are needed to determine whether Ltheanine can be effective as a cancer preventive agent against carcinogenesis.

\section{Conclusions and Perspectives}

Many common cancers happen at an older age of human life. Interestingly, both slowly aging centenarians and naked molerats are particularly resistant to cancer development [192, 193], whereas, rapidly aging mice develop cancer within 2 years [192]. Evidence has also emerged that slowing down aging can, in turn, delay cancer occurrence, improve cancer prognosis, and increase the overall quality of cancer patients' lives. Therefore, we can argue that anti-aging agents are a viable option for cancer prevention in the elderly.

Nutrient-sensing pathways, such as insulin/IGF-1, mTOR, AMPK, and sirtuins play major roles in aging-associated cancer initiation and progression. Aberrant alteration in these nutrient-sensing pathways are associated with increased risk of other age-related diseases and conditions, such as type 2 diabetes, obesity, hyperglycemia and hyperinsulinemia, and metabolic syndrome. These pathways mainly regulate cell metabolism and the whole body metabolism. Therefore, unhealthy lifestyles such as overeating and consumption of highfat diet, can lead to changes in these nutrient-sensing pathways and increased cancer risk.

Agents with both anti-aging and anti-cancer effects (e.g., metformin, resveratrol, Rhodiola, aspirin, lithocholic acid, and L-theanine) often confer cellular and systemic benefits of metabolism similar to the effect of positive lifestyle interventions. Chemoprevention by these agents could potentially target normal postmitotic cells (i.e., aging cells) and no selection for resistance will be expected. It is also possible that the chemopreventive efficacy of these agents does not depend on the genetic background of cancer cells and these agents may be able to prevent cancer even with the loss of tumor suppressors (e.g., p53 and Rb) or the gain of oncogenic functions (e.g., ErbB activation). Therefore, agents with both anti-aging and anti-cancer effects are very promising candidates for cancer prevention as summarized in Table 1.

Many basic questions regarding how aging leads to carcinogenesis and cancer progression remain unanswered. Whether cancer prevention by agents with both anti-aging and anti-cancer properties can target cancer cells directly and/or indirectly by slowing down the aging process is still undetermined. However, it is clear that nutrient-sensing pathways governing cellular metabolism and growth are common alterations in both cancer and aging. Agents targeting these pathways are moving to the forefront of cancer and aging research as a safe and efficacious means to reduce cancer morbidity and mortality as well as improve cancer prognosis and overall quality of life.

Acknowledgments This work was supported in part by NIH award 5R01CA122558-05 and 1R21CA152804-01A1 (to X. Zi.).

\section{Compliance with Ethics Guidelines}

Conflict of Interest Noriko N. Yokoyama, Andria Denmon, Edward M. Uchio, Mark Jordan, Dan Mercola, and Xiaolin Zi declare that they have no conflict of interest.

Human and Animal Rights and Informed Consent This article does not contain any studies with human or animal subjects performed by any of the authors.

\section{References}

Papers of particular interest, published recently, have been highlighted as:

- Of importance

•• Of major importance

1. American Cancer Society: http://www.cancer.org/research/ cancerfactsfigures/globalcancerfactsfigures/global-facts-figures2nd-ed; Global Cancer Facts \& Figures 2nd Edition accessed on December 3, 2014

2. Popat K, McQueen K, Feeley TW. The global burden of cancer. Best Pract Res Clin Anaesthesiol. 2013;27:399-408.

3. López-Otín C, Blasco MA, Partridge L, Serrano M, Kroemer G. The hallmarks of aging. Cell. 2013;153:1194-217.

4. Kirkwood TB. Understanding the odd science of aging. Cell. 2005;120:437-47.

5. Kirkwood T. Why women live longer. Stress alone does not explain the longevity gap. Sci Am. 2010;303:34-5.

6. Orozco-Solis R, Sassone-Corsi P. Circadian clock: linking epigenetics to aging. Curr Opin Genet Dev. 2014;26C:66-72.

7. Draznin B, Wang C, Adochio R, Leitner JW, Cornier MA. Effect of dietary macronutrient composition on AMPK and SIRT1 expression and activity in human skeletal muscle. Horm Metab Res. 2012;44:650-5.

8. Rizza W, Veronese N, Fontana L. What are the roles of calorie restriction and diet quality in promoting healthy longevity? Ageing Res Rev. 2014;13:38-45.

9. Berstein LM. Metformin in obesity, cancer and aging: addressing controversies. Aging (Albany NY). 2012;4:320-9.

10. Wan QL, Zheng SQ, Wu GS, Luo HR. Aspirin extends the lifespan of Caenorhabditis elegans via AMPK and DAF-16/ FOXO in dietary restriction pathway. Exp Gerontol. 2013;48: 499-506.

11. Marchal J, Pifferi F, Aujard F. Resveratrol in mammals: effects on aging biomarkers, age-related diseases, and life span. Ann N Y Acad Sci. 2013;1290:67-73.

12. Schriner SE, Lee K, Truong S, Salvadora KT, Maler S, Nam A, et al. Extension of Drosophila lifespan by Rhodiola rosea through a mechanism independent from dietary restriction. PLoS One. 2013;8:e63886. 
13. Gospodaryov DV, Yurkevych IS, Jafari M, Lushchak VI, Lushchak OV. Lifespan extension and delay of age-related functional decline caused by Rhodiola rosea depends on dietary macronutrient balance. Longev Healthspan. 2013;2:5.

14. Bayliak MM, Burdyliuk NI, Izers'ka LI, Lushchak VI. Concentration-dependent effects of rhodiola rosea on long-term survival and stress resistance of yeast Saccharomyces cerevisiae: the involvement of YAP 1 and MSN2/4 regulatory proteins. Dose Response. 2013;12:93-109.

15. Cha YI, Kim HS. Emerging role of sirtuins on tumorigenesis: possible link between aging and cancer. BMB Rep. 2013;46: 429-38.

16. Pollak $M$. The insulin and insulin-like growth factor receptor family in neoplasia: an update. Nat Rev Cancer. 2012;12:159-69.

17. Liang J, Mills GB. AMPK: a contextual oncogene or tumor suppressor? Cancer Res. 2013;73:2929-35.

18. Cornu M, Albert V, Hall MN. mTOR in aging, metabolism, and cancer. Curr Opin Genet Dev. 2013;23:53-62.

19. Fahey JW, Kensler TW. Health span extension through green chemoprevention. Virtual Mentor. 2013;15:311-8.

20. Blagosklonny MV. Prevention of cancer by inhibiting aging. Cancer Biol Ther. 2008;7:1520-4.

21. Steward WP, Brown K. Cancer chemoprevention: a rapidly evolving field. Br J Cancer. 2013;109:1-7.

22. Junnila RK, List EO, Berryman DE, Murrey JW, Kopchick JJ. The GH/IGF-1 axis in ageing and longevity. Nat Rev Endocrinol. 2013;9:366-76.

23. Milman S, Atzmon G, Huffman DM, Wan J, Crandall JP, Cohen P, et al. Low insulin-like growth factor-1 level predicts survival in humans with exceptional longevity. Aging Cell. 2014;13:769-71.

24. Fontana L, Partridge L, Longo VD. Extending healthy life spanfrom yeast to humans. Science. 2010;328:321-6.

25. Schumacher B, van der Pluijm I, Moorhouse MJ, Kosteas T, Robinson AR, Suh Y, et al. Delayed and accelerated aging share common longevity assurance mechanisms. PLoS Genet. 2008;4: e1000161.

26. Arum O, Boparai RK, Saleh JK, Wang F, Dirks AL, Turner JG, et al. Specific suppression of insulin sensitivity in growth hormone receptor gene-disrupted (GHR-KO) mice attenuates phenotypic features of slow aging. Aging Cell. 2014;13:981-1000.

27. Holzenberger M, Dupont J, Ducos B, Leneuve P, Géloën A, Even $\mathrm{PC}$, et al. IGF-1 receptor regulates lifespan and resistance to oxidative stress in mice. Nature. 2003;421:182-7.

28. Marino G, Ugalde AP, AF F n, Osorio FG, Fueyo A, Freije JM, et al. Insulin-like growth factor 1 treatment extends longevity in a mouse model of human premature aging by restoring somatotroph axis function. Proc Natl Acad Sci U S A. 2010;107:16268-73.

29. Besson A, Salemi S, Gallati S, Jenal A, Horn R, Mullis PS, et al. Reduced longevity in untreated patients with isolated growth hormone deficiency. J Clin Endocrinol Metab. 2003;88:3664-7.

30. Bartke A. Minireview: role of the growth hormone/insulin-like growth factor system in mammalian aging. Endocrinology. 2005;146:3718-23

31. Guevara-Aguirre J, Balasubramanian P, Guevara-Aguirre M, Wei M, Madia F, Cheng CW, et al. Growth hormone receptor deficiency is associated with a major reduction in pro-aging signaling, cancer, and diabetes in humans. Sci Transl Med. 2011;3:70.

32. Milman S, Atzmon G, Huffman DM, Wan J, Crandall JP, Cohen P, et al. Low insulin-like growth factor-1 level predicts survival in humans with exceptional longevity. Aging Cell. 2014;13:769-71. This study reported that low IGF-1 levels are associated with longer survival in females and individuals with a history of cancer, who are at age between the age of 90 and 99.

33. Anisimov VN, Bartke A. The key role of growth hormone-insulinIGF-1 signaling in aging and cancer. Crit Rev Oncol Hematol. 2013;87:201-23.
34. Westley RL, May FE. A twenty-first century cancer epidemic caused by obesity: the involvement of insulin, diabetes, and insulin-like growth factors. Int J Endocrinol. 2013;2013:632461.

35. Chan JM, Stampfer MJ, Giovannucci E, Gann PH, Ma J, Wilkinson P, et al. Plasma insulin-like growth factor-I and prostate cancer risk: a prospective study. Science. 1998;279:563-6.

36. Huang YF, Cheng WF, Wu YP, Cheng YM, Hsu KF, Chou CY. Circulating IGF system and treatment outcome in epithelial ovarian cancer. EndocrInol Relat Cancer. 2014;21:217-29.

37. Kaaks R, Johnson T, Tikk K, Sookthai D, Tjønneland A, Roswall $\mathrm{N}$, et al. Insulin-like growth factor I and risk of breast cancer by age and hormone receptor status-A prospective study within the EPIC cohort. Int J Cancer. 2014;134:2683-90.

38. Soubry A, Il'yasova D, Sedjo R, Wang F, Byers T, Rosen C, et al. Increase in circulating levels of IGF-1 and IGF-1/IGFBP-3 molar ratio over a decade is associated with colorectal adenomatous polyps. Int J Cancer. 2012;131:512-7.

39. Sell C, Rubini M, Rubin R, Liu JP, Efstratiadis A, Baserga R. Simian virus 40 large tumor antigen is unable to transform mouse embryonic fibroblasts lacking type 1 insulin-like growth factor receptor. Proc Natl Acad Sci U S A. 1993;90:11217-21.

40. Hursting SD, Perkins SN, Lavigne JA, Beltran L, Haines DC, Hill $\mathrm{HL}$, et al. Urothelial overexpression of insulin-like growth factor-1 increases susceptibility to p-cresidine-induced bladder carcinogenesis in transgenic mice. Mol Carcinog. 2009;48:671-7.

41. Ma J, Giovannucci E, Pollak M, Leavitt A, Tao Y, Gaziano JM, et al. A prospective study of plasma C-peptide and colorectal cancer risk in men. J Natl Cancer Inst. 2004;96:546-53.

42. Harrela M, Koistinen H, Kaprio J, Lehtovirta M, Tuomilehto J, Eriksson J, et al. Genetic and environmental components of interindividual variation in circulating levels of IGF-I, IGF-II, IGFBP1, and IGFBP-3. J Clin Invest. 1996;98:2612-5.

43. Sengupta S, Peterson TR, Laplante M, Oh S, Sabatini DM. mTORC 1 controls fasting-induced ketogenesis and its modulation by ageing. Nature. 2010;468:1100-4.

44. Powers 3rd RW, Kaeberlein M, Caldwell SD, Kennedy BK, Fields S. Extension of chronological life span in yeast by decreased TOR pathway signaling. Genes Dev. 2006;20:174-84.

45. Robida-Stubbs S, Glover-Cutter K, Lamming DW, Mizunuma M, Narasimhan SD, Neumann-Haefelin E, et al. TOR signaling and rapamycin influence longevity by regulating $\mathrm{SKN}-1 / \mathrm{Nrf}$ and DAF-16/FoxO. Cell Metab. 2012;15:713-24.

46. Bjedov I, Toivonen JM, Kerr F, Slack C, Jacobson J, Foley A, et al. Mechanisms of life span extension by rapamycin in the fruit fly Drosophila melanogaster. Cell Metab. 2010;11:35-46.

47. Harrison DE, Strong R, Sharp ZD, Nelson JF, Astle CM, Flurkey $\mathrm{K}$, et al. Rapamycin fed late in life extends lifespan in genetically heterogeneous mice. Nature. 2009;460:392-5.

48. Anisimov VN, Zabezhinski MA, Popovich IG, Piskunova TS, Semenchenko AV, Tyndyk ML, et al. Rapamycin extends maximal lifespan in cancer-prone mice. Am J Pathol. 2010;176:20927.

49. Lamming DW, Ye L, Katajisto P, Goncalves MD, Saitoh M, Stevens DM, et al. Rapamycin-induced insulin resistance is mediated by mTORC2 loss and uncoupled from longevity. Science. 2012;335:1638-43.

50. Neff F, Flores-Dominguez D, Ryan DP, Horsch M, Schröder S, Adler T, et al. Rapamycin extends murine lifespan but has limited effects on aging. J Clin Invest. 2013;123:3272-91.

51. Leslie M. Biomedicine. A putative antiaging drug takes a step from mice to men. Science. 2013;342:789.

52. Howell JJ, Ricoult SJ, Ben-Sahra I, Manning BD. A growing role for mTOR in promoting anabolic metabolism. Biochem Soc Trans. 2013;41:906-12.

53. Blagosklonny MV. Molecular damage in cancer: an argument for mTOR-driven aging. Aging. 2011;3:1130-41. 
54. Shaw RJ, Cantley LC. Ras, PI(3)K and mTOR signalling controls tumour cell growth. Nature. 2006;441:424-30.

55. Blagosklonny MV. Rapalogs in cancer prevention: anti-aging or anticancer? Cancer Biol Ther. 2012;13:1349-54.

56. Porta C, Paglino C, Mosca A. Targeting PI3K/Akt/mTOR signaling in cancer. Front Oncol. 2014;4:64.

57. Markman B, Dienstmann R, Tabernero J. Targeting the PI3K/Akt/ mTOR pathway - beyond rapalogs. Oncotarget. 2010;1:530-43.

58. Lebwohl D, Anak O, Sahmoud T, Klimovsky J, Elmroth I, Haas T, et al. Development of everolimus, a novel oral mTOR inhibitor, across a spectrum of diseases. Ann N Y Acad Sci. 2013;1291:14-32.

59. Rodon J, Dienstmann R, Serra V, Tabernero J. Development of PI3K inhibitors: lessons learned from early clinical trials. Nat Rev Clin Oncol. 2013;10:143-53.

60. Memmott RM, Dennis PA. The role of the Akt/mTOR pathway in tobacco carcinogen-induced lung tumorigenesis. Clin Cancer Res. 2010;16:4-10.

61. Martins F, de Oliveira MA, Wang Q, Sonis S, Gallottini M, George S, et al. A review of oral toxicity associated with mTOR inhibitor therapy in cancer patients. Oral Oncol. 2013;49:293-8.

62. Danesi R, Boni JP, Ravaud A. Oral and intravenously administered mTOR inhibitors for metastatic renal cell carcinoma: pharmacokinetic considerations and clinical implications. Cancer Treat Rev. 2013;39:784-92.

63. Fulco M, Sartorelli V. Comparing and contrasting the roles of AMPK and SIRT1 in metabolic tissues. Cell Cycle. 2008;7:3669-79.

64. Apfeld J, O'Connor G, McDonagh T, DiStefano PS, Curtis R. The AMP-activated protein kinase AAK-2 links energy levels and insulin-like signals to lifespan in C. elegans. Genes Dev. 2004;18:3004-9.

65. Stenesen D, Suh JM, Seo J, Yu K, Lee KS, Kim JS, et al. Adenosine nucleotide biosynthesis and AMPK regulate adult life span and mediate the longevity benefit of caloric restriction in flies. Cell Metab. 2013;17:101-12.

66. Funakoshi M, Tsuda M, Muramatsu K, Hatsuda H, Morishita S, Aigaki T. A gain-of-function screen identifies wdb and $1 \mathrm{~kb} 1$ as lifespan-extending genes in Drosophila. Biochem Biophys Res Commun. 2011;405:667-72.

67. Mair W, Morantte I, Rodrigues AP, Manning G, Montminy M, Shaw RJ, et al. Lifespan extension induced by AMPK and calcineurin is mediated by CRTC-1 and CREB. Nature. 2011;470: 404-8.

68. Greer EL, Brunet A. Different dietary restriction regimens extend lifespan by both independent and overlapping genetic pathways in C. elegans. Aging Cell. 2009;8:113-27.

69. Salminen A, Kaarniranta K. AMP-activated protein kinase (AMPK) controls the aging process via an integrated signaling network. Ageing Res Rev. 2012;11:230-41.

70. Cool B, Zinker B, Chiou W, Kifle L, Cao N, Perham M, et al. Identification and characterization of a small molecule AMPK activator that treats key components of type 2 diabetes and the metabolic syndrome. Cell Metab. 2006;3:403-16.

71.• Hawley SA, Fullerton MD, Ross FA, Schertzer JD, Chevtzoff C, Walker KJ, et al. The ancient drug salicylate directly activates AMP-activated protein kinase. Science. 2012;336:918-22. This paper demonstrated that salicylate, the major metabolite of aspirin, binds to AMPK $\beta 1$ and causes its allosteric activation to low plasma fatty acids in vivo in mice.

72. Li YY, Yu LF, Zhang LN, Qiu BY, Su MB, Wu F, et al. Novel small-molecule AMPK activator orally exerts beneficial effects on diabetic db/db mice. Toxicol Appl Pharmacol. 2013;273:325-34.

73. Ayyadevara S, Bharill P, Dandapat A, Hu C, Khaidakov M, Mitra $\mathrm{S}$, et al. Aspirin inhibits oxidant stress, reduces age-associated functional declines, and extends lifespan of Caenorhabditis elegans. Antioxid Redox Signal. 2013;18:481-90.

74. Pierotti MA, Berrino F, Gariboldi M, Melani C, Mogavero A, Negri $\mathrm{T}$, et al. Targeting metabolism for cancer treatment and prevention: metformin, an old drug with multi-faceted effects. Oncogene. 2013;32:1475-87.

75. Gill RK, Yang SH, Meerzaman D, Mechanic LE, Bowman ED, Jeon HS, et al. Frequent homozygous deletion of the LKB1/ STK11 gene in non-small cell lung cancer. Oncogene. 2011;30: 3784-91.

76. Hearle N, Schumacher V, Menko FH, Olschwang S, Boardman LA, Gille JJ, et al. Frequency and spectrum of cancers in the Peutz-Jeghers syndrome. Clin Cancer Res. 2006;12:3209-15.

77. Shackelford DB, Vasquez DS, Corbeil J, Wu S, Leblanc M, Wu CL, et al. mTOR and HIF-1alpha-mediated tumor metabolism in an LKB1 mouse model of Peutz-Jeghers syndrome. Proc Natl Acad Sci U S A. 2009;106:11137-42.

78. Park HU, Suy S, Danner M, Dailey V, Zhang Y, Li H, et al. AMPactivated protein kinase promotes human prostate cancer cell growth and survival. Mol Cancer Ther. 2009;8:733-41.

79. Kim YH, Liang H, Liu X, Lee JS, Cho JY, Cheong JH, et al. AMPKalpha modulation in cancer progression: multilayer integrative analysis of the whole transcriptome in Asian gastric cancer. Cancer Res. 2012;72:2512-21.

80. Li C, Liu VW, Chiu PM, Chan DW, Ngan HY. Over-expressions of AMPK subunits in ovarian carcinomas with significant clinical implications. BMC Cancer. 2012;12:357.

81. Guarente L. Introduction: sirtuins in aging and diseases. Methods Mol Biol. 2013;1077:3-10.

82. Alcendor RR, Gao S, Zhai P, Zablocki D, Holle E, Yu X, et al. Sirt1 regulates aging and resistance to oxidative stress in the heart. Circ Res. 2007;100:1512-21.

83. Zuo L, Khan RS, Lee V, Dine K, Wu W, Shindler KS. SIRT1 promotes RGC survival and delays loss of function following optic nerve crush. Invest Ophthalmol Vis Sci. 2013;54:5097-102.

84. Brown K, Xie S, Qiu X, Mohrin M, Shin J, Liu Y, et al. SIRT3 reverses aging-associated degeneration. Cell Rep. 2013;3:319-27.

85. Lombard DB, Zwaans BM. SIRT3: as simple as it seems? Gerontology. 2014;60:56-64.

86. Kanfi Y, Naiman S, Amir G, Peshti V, Zinman G, Nahum L, et al. The sirtuin SIRT6 regulates lifespan in male mice. Nature. 2012;483:218-21. This publication shows that the overexpression of Sirt6 decreases plasma IGF-1 levels and significantly extends the lifespan of male mice but not female mice.

87. Mostoslavsky R, Chua KF, Lombard DB, Pang WW, Fischer MR, Gellon L, et al. Genomic instability and aging-like phenotype in the absence of mammalian SIRT6. Cell. 2006;124:315-29.

88. Sundaresan NR, Vasudevan P, Zhong L, Kim G, Samant S, Parekh V, et al. The sirtuin SIRT6 blocks IGF-Akt signaling and development of cardiac hypertrophy by targeting c-Jun. Nat Med. 2012;18:1643-50.

89. Baur JA, Ungvari Z, Minor RK, Le Couteur DG, de Cabo R. Are sirtuins viable targets for improving healthspan and lifespan? Nat Rev Drug Discov. 2012;11:443-61.

90. de Oliveira MV, Andrade JM, Paraíso AF, Santos SH. Sirtuins and cancer: new insights and cell signaling. Cancer Invest. 2013;31: 645-53.

91. Hiratsuka M, Inoue T, Toda T, Kimura N, Shirayoshi Y, Kamitani $\mathrm{H}$, et al. Proteomics based identification of differentially expressed genes in human gliomas: down-regulation of SIRT2 gene. Biochem Biophys Res Commun. 2003;309:558-66.

92. Lai CC, Lin PM, Lin SF, Hsu CH, Lin HC, Hu ML, et al. Altered expression of SIRT gene family in head and neck squamous cell carcinoma. Tumour Biol. 2013;34:1847-54.

93. Ong CA, Shapiro J, Nason KS, Davison JM, Liu X, Ross-Innes C, et al. Three-gene immunohistochemical panel adds to clinical 
staging algorithms to predict prognosis for patients with esophageal adenocarcinoma. J Clin Oncol. 2013;31:1576-82.

94. McGlynn LM, Zino S, MacDonald AI, Curle J, Reilly JE, Mohammed ZM, et al. SIRT2: tumour suppressor or tumour promoter in operable breast cancer? Eur J Cancer. 2014;50:290-301.

95. Kim HS, Vassilopoulos A, Wang RH, Lahusen T, Xiao Z, Xu X, et al. SIRT2 maintains genome integrity and suppresses tumorigenesis through regulating APC/C activity. Cancer Cell. 2011;20:487-99.

96. Finley LW, Haigis MC. Metabolic regulation by SIRT3: implications for tumorigenesis. Trends Mol Med. 2012;18:516-23.

97. Kim HS, Patel K, Muldoon-Jacobs K, Bisht KS, Aykin-Burns N, Pennington JD, et al. SIRT3 is a mitochondria-localized tumor suppressor required for maintenance of mitochondrial integrity and metabolism during stress. Cancer Cell. 2010;17:41-52.

98. Jeong SM, Xiao C, Finley LW, Lahusen T, Souza AL, Pierce K, et al. SIRT4 has tumor-suppressive activity and regulates the cellular metabolic response to DNA damage by inhibiting mitochondrial glutamine metabolism. Cancer Cell. 2013;23:450-63.

99. Sebastián C, Zwaans BM, Silberman DM, Gymrek M, Goren A, Zhong L, et al. The histone deacetylase SIRT6 is a tumor suppressor that controls cancer metabolism. Cell. 2012;151:1185-99.

100. Marquardt JU, Fischer K, Baus K, Kashyap A, Ma S, Krupp M, et al. Sirtuin-6-dependent genetic and epigenetic alterations are associated with poor clinical outcome in hepatocellular carcinoma patients. Hepatology. 2013;58:1054-64

101. Bauer I, Grozio A, Lasigliè D, Basile G, Sturla L, Magnone M, et al. The $\mathrm{NAD}^{+}$-dependent histone deacetylase SIRT6 promotes cytokine production and migration in pancreatic cancer cells by regulating Ca2+ responses. J Biol Chem. 2012;287:40924-37.

102. Liu PY, Xu N, Malyukova A, Scarlett CJ, Sun YT, Zhang XD, et al. The histone deacetylase SIRT2 stabilizes Myc oncoproteins. Cell Death Differ. 2013;20:503-14.

103. Haigis MC, Sinclair DA. Mammalian sirtuins: biological insights and disease relevance. Annu Rev Pathol. 2010;5:253-95.

104. Snell TW. Rotifers as models for the biology of aging. Int Rev Hydrobiol. 2014;99:84-95.

105. Guarente L. Calorie restriction and sirtuins revisited. Genes Dev. 2013;27:2072-85.

106. Colman RJ, Beasley TM, Kemnitz JW, Johnson SC, Weindruch R, Anderson RM. Caloric restriction reduces age-related and allcause mortality in rhesus monkeys. Nat Commun. 2014;5:3557.

107. Fontana L, Meyer TE, Klein S, Holloszy JO. Long-term calorie restriction is highly effective in reducing the risk for atherosclerosis in humans. Proc Natl Acad Sci U S A. 2004;101:6659-63.

108. Heilbronn LK, de Jonge L, Frisard MI, DeLany JP, Larson-Meyer $\mathrm{DE}$, Rood J, et al. Effect of 6-month calorie restriction on biomarkers of longevity, metabolic adaptation, and oxidative stress in overweight individuals: a randomized controlled trial. JAMA. 2006;295:1539-48

109. Racette SB, Weiss EP, Villareal DT, Arif H, Steger-May K, Schechtman KB, et al. One year of caloric restriction in humans: feasibility and effects on body composition and abdominal adipose tissue. Washington School of Medicine CALERIE Team. J Gerontol A Biol Sci Med Sci. 2006;61:943-50.

110. Higami Y, Tsuchiya T, Chiba T, Yamaza H, Muraoka I, Hirose M, et al. Hepatic gene expression profile of lipid metabolism in rats: impact of caloric restriction and growth hormone/insulin-like growth factor-1 suppression. J Gerontol A Biol Sci Med Sci. 2006;61:1099-110.

111. Gesing A, Al-Regaiey KA, Bartke A, Masternak MM. Growth hormone abolishes beneficial effects of calorie restriction in long-lived Ames dwarf mice. Exp Gerontol. 2014;58:219-29.

112. Blagosklonny MV. Calorie restriction: decelerating mTOR-driven aging from cells to organisms (including humans). Cell Cycle. 2010;9:683-8.
113. Moroz N, Carmona JJ, Anderson E, Hart AC, Sinclair DA, Blackwell TK. Dietary restriction involves $\mathrm{NAD}(+)$-dependent mechanisms and a shift toward oxidative metabolism. Aging Cell. 2014;13:1075-85.

114. Robertson LT, Mitchell JR. Benefits of short-term dietary restriction in mammals. Exp Gerontol. 2013;48:1043-8.

115. Hursting SD, Smith SM, Lashinger LM, Harvey AE, Perkins SN. Calories and carcinogenesis: lessons learned from 30 years of calorie restriction research. Carcinogenesis. 2010;31:83-9.

116. De Lorenzo MS, Baljinnyam E, Vatner DE, Abarzúa P, Vatner SF, Rabson AB. Caloric restriction reduces growth of mammary tumors and metastases. Carcinogenesis. 2011;32:1381-7.

117. Dunn SE, Kari FW, French J, Leininger JR, Travlos G, Wilson R, et al. Dietary restriction reduces insulin-like growth factor I levels, which modulates apoptosis, cell proliferation, and tumor progression in p53-deficient mice. Cancer Res. 1997;57:4667-72.

118. De Haes W, Frooninckx L, Van Assche R, Smolders A, Depuydt $\mathrm{G}$, Billen $\mathrm{J}$, et al. Metformin promotes lifespan through mitohormesis via the peroxiredoxin PRDX-2. Proc Natl Acad Sci U S A. 2014;111:E2501-9.

119. Cabreiro F, Au C, Leung KY, Vergara-Irigaray N, Cochemé HM, Noori $\mathrm{T}$, et al. Metformin retards aging in $\mathrm{C}$. elegans by altering microbial folate and methionine metabolism. Cell. 2013;153:228-39.

120. Martin-Montalvo A, Mercken EM, Mitchell SJ, Palacios HH, Mote PL, Scheibye-Knudsen M, et al. Metformin improves healthspan and lifespan in mice. Nat Commun. 2013;4:2192.

121. Ma TC, Buescher JL, Oatis B, Funk JA, Nash AJ, Carrier RL, et al. Metformin therapy in a transgenic mouse model of Huntington's disease. Neurosci Lett. 2007;411:98-103.

122. Spindler SR. Use of microarray biomarkers to identify longevity therapeutics. Aging Cell. 2006;5:39-50.

123. Bannister CA, Holden SE, Jenkins-Jones S, Morgan CL, Halcox JP, Schernthaner G, et al. Can people with type 2 diabetes live longer than those without? A comparison of mortality in people initiated with metformin or sulphonylurea monotherapy and matched, non-diabetic controls. Diabetes Obes Metab. 2014;16: $1165-73$

124. Giovannucci E, Harlan DM, Archer MC, Bergenstal RM, Gapstur SM, Habel LA, et al. Diabetes and cancer: a consensus report. Diabetes Care. 2010;33:1674-85.

125. Vigneri P, Frasca F, Sciacca L, Pandini G, Vigneri R. Diabetes and cancer. Endocrinol Relat Cancer. 2009;16:1103-23.

126. Larsson SC, Mantzoros CS, Wolk A. Diabetes mellitus and risk of breast cancer: a meta-analysis. Int J Cancer. 2007;121:856-62.

127. Smith U, Gale EM. Cancer and diabetes: are we ready for prime time? Diabetologia. 2010;53:1541-4.

128. Bonovas S, Filioussi K, Tsantes A. Diabetes mellitus and risk of prostate cancer: a meta-analysis. Diabetologia. 2004;47:1071-8.

129. Ruiter R, Visser LE, van Herk-Sukel MP, Coebergh JW, Haak HR, Geelhoed-Duijvestijn PH, et al. Lower risk of cancer in patients on metformin in comparison with those on sulfonylurea derivatives: results from a large population-based follow-up study. Diabetes Care. 2012;35:119-24. This large pharmaco-epidemiological study analyzed drug dispensing records from community pharmacies of 2.5 million individuals in the Netherlands. It shows that metformin use is associated with a lower risk of cancer in general (hazard ratio 0.90 [95\% CI 0.88-0.91]) compared with use of sulfonylurea derivatives.

130. Lee JH, Kim TI, Jeon SM, Hong SP, Cheon JH, Kim WH. The effects of metformin on the survival of colorectal cancer patients with diabetes mellitus. Int J Cancer. 2012;131:752-9.

131. Romero IL, McCormick A, McEwen KA, Park S, Karrison T, Yamada SD, et al. Relationship of Type II diabetes and metformin use to ovarian cancer progression, survival, and chemosensitivity. Obstet Gynecol. 2012;119:61-7. 
132. Bayraktar S, Hernadez-Aya LF, Lei X, Meric-Bernstam F, Litton JK, Hsu L, et al. Effect of metformin on survival outcomes in diabetic patients with triple receptor negative breast cancer. Cancer. 2012;118:1202-11.

133. Patel T, Kirby W, Hruby G, Benson MC, McKiernan JM, Badani K. Clinical outcomes after radical prostatectomy in diabetic patients treated with metformin. Urology. 2010;76:1240-4.

134. www.ClinicalTrials.gov Accessed on December 7, 2014.

135. Campagnoli C, Pasanisi $\mathrm{P}$, Abbà $\mathrm{C}$, Ambroggio S, Biglia N, Brucato $\mathrm{T}$, et al. Effect of different doses of metformin on serum testosterone and insulin in non-diabetic women with breast cancer: a randomized study. Clin Breast Cancer. 2012;12:175-82.

136. Hosono K, Endo H, Takahashi H, Sugiyama M, Sakai E, Uchiyama T, et al. Metformin suppresses colorectal aberrant crypt foci in a short-term clinical trial. Cancer Prev Res (Phila). 2010;3: 1077-83.

137. Algire C, Zakikhani M, Blouin MJ, Shuai JH, Pollak M. Metformin attenuates the stimulatory effect of a high-energy diet on in vivo LLC1 carcinoma growth. Endocrinol Relat Cancer. 2008; 15:833-9.

138. Zhu P, Davis M, Blackwelder AJ, Bachman N, Liu B, Edgerton S, et al. Metformin selectively targets tumor-initiating cells in ErbB2overexpressing breast cancer models. Cancer Prev Res (Phila). 2014;7:199-210.

139. Checkley LA, Rho O, Angel JM, Cho J, Blando J, Beltran L, et al. Metformin inhibits skin tumor promotion in overweight and obese mice. Cancer Prev Res (Phila). 2014;7:54-64.

140. Bridges HR, Jones AJ, Pollak MN, Hirst J. Effects of metformin and other biguanides on oxidative phosphorylation in mitochondria. Biochem J. 2014;462:475-87.

141. Hirsch HA, Iliopoulos D, Tsichlis PN, Struhl K. Metformin selectively targets cancer stem cells, and acts together with chemotherapy to block tumor growth and prolong remission. Cancer Res. 2009;69:7507-11.

142. Yan L, Zhou J, Gao Y, Ghazal S, Lu L, Bellone S, et al. Regulation of tumor cell migration and invasion by the H19/let-7 axis is antagonized by metformin-induced DNA methylation. Oncogene. 2014.

143. Cufí S, Vazquez-Martin A, Oliveras-Ferraros C, Quirantes R, Segura-Carretero A, Micol V, et al. Metformin lowers the threshold for stress-induced senescence: a role for the microRNA-200 family and miR-205. Cell Cycle. 2012;11:1235-46.

144. Vazquez-Martin A, Oliveras-Ferraros C, Cufi S, Martin-Castillo $\mathrm{B}$, Menendez JA. Metformin activates an ataxia telangiectasia mutated (ATM)/Chk2-regulated DNA damage-like response. Cell Cycle. 2011;10:1499-501.

145. Menendez JA, Oliveras-Ferraros C, Cufí S, Corominas-Faja B, Joven J, Martin-Castillo B, et al. Metformin is synthetically lethal with glucose withdrawal in cancer cells. Cell Cycle. 2012;11: 2782-92.

146. Chen L, Shu Y, Liang X, Chen EC, Yee SW, Zur AA, et al. OCT1 is a high-capacity thiamine transporter that regulates hepatic steatosis and is a target of metformin. Proc Natl Acad Sci U S A. 2014;111:9983-8.

147. Renaud S, de Lorgeril M. Wine, alcohol, platelets, and the French paradox for coronary heart disease. Lancet. 1992;339:1523-6.

148. Howitz KT, Howitz KT, Bitterman KJ, Cohen HY, Lamming DW, Lavu S, et al. Small molecule activators of sirtuins extend Saccharomyces cerevisiae lifespan. Nature. 2003;425:191-6.

149. Agarwal B, Baur JA. Resveratrol and life extension. Ann N Y Acad Sci. 2011;1215:138-43.

150. Barger JL, Kayo T, Vann JM, Arias EB, Wang J, Hacker TA, et al. A low dose of dietary resveratrol partially mimics caloric restriction and retards aging parameters in mice. PLoS One. 2008;3:e2264.
151. Valenzano DR, Terzibasi E, Genade T, Cattaneo A, Domenici L, Cellerino A. Resveratrol prolongs lifespan and retards the onset of age-related markers in a short-lived vertebrate. Curr Biol. 2006;16: 296-300.

152. Kaeberlein M, McDonagh T, Heltweg B, Hixon J, Westman EA, Caldwell SD. Substrate-specific activation of sirtuins by resveratrol. J Biol Chem. 2005;280:17038-45.

153. Wang C, Wheeler CT, Alberico T, Sun X, Seeberger J, Laslo M, et al. The effect of resveratrol on lifespan depends on both gender and dietary nutrient composition in Drosophila melanogaster. Age. 2013;35:69-81.

154. Pearson KJ, Baur JA, Lewis KN, Peshkin L, Price NL, Labinskyy $\mathrm{N}$, et al. Resveratrol delays age-related deterioration and mimics transcriptional aspects of dietary restriction without extending life span. Cell Metab. 2008;8:157-68.

155. Lagouge M, Argmann C, Gerhart-Hines Z, Meziane H, Lerin C, Daussin F, et al. Resveratrol improves mitochondrial function and protects against metabolic disease by activating SIRT1 and PGC1alpha. Cell. 2006;127:1109-22.

156.• Park SJ, Ahmad F, Philp A, Baar K, Williams T, Luo H, et al. Resveratrol ameliorates aging-related metabolic phenotypes by inhibiting cAMP phosphodiesterases. Cell. 2012;148:421-33. This article provides a novel mechanism of resveratrol's action, which resveratrol competitively inhibits cAMPdegrading phosphodiesterases, leading to activate the CamKK $\beta$-AMPK pathway and Sirt1.

157. Brasnyó $\mathrm{P}$, Molnár GA, Mohás M, Markó L, Laczy B, Cseh J, et al. Resveratrol improves insulin sensitivity, reduces oxidative stress and activates the Akt pathway in type 2 diabetic patients. $\mathrm{Br}$ J Nutr. 2011;106:383-9.

158. Bhatt JK, Thomas S, Nanjan MJ. Resveratrol supplementation improves glycemic control in type 2 diabetes mellitus. Nutr Res. 2012;32:537-41.

159. Subramanian L, Youssef S, Bhattacharya S, Kenealey J, Polans AS, van Ginkel PR. Resveratrol: challenges in translation to the clinic - a critical discussion. Clin Cancer Res. 2010;16:5942-8.

160. Athar M, Back JH, Tang X, Kim KH, Kopelovich L, Bickers DR, et al. Resveratrol: a review of preclinical studies for human cancer prevention. Toxicol Appl Pharmacol. 2007;224:274-83.

161. Nguyen AV, Martinez M, Stamos MJ, Moyer MP, Planutis K, Hope C, et al. Results of a phase I pilot clinical trial examining the effect of plant-derived resveratrol and grape powder on Wnt pathway target gene expression in colonic mucosa and colon cancer. Cancer Manag Res. 2009;1:25-37.

162. Walle T, Hsieh F, DeLegge MH, Oatis Jr JE, Walle UK. High absorption but very low bioavailability of oral resveratrol in humans. Drug Metab Dispos. 2004;32:1377-82.

163. Szewczuk LM, Forti L, Stivala LA, Penning TM. Resveratrol is a peroxidase-mediated inactivator of COX-1 but not COX-2: mechanistic approach to the design of COX-1 selective agents. J Biol Chem. 2004;279:22727-37.

164. Zykova TA, Zhu F, Zhai X, Ma WY, Ermakova SP, Lee KW, et al. Resveratrol directly targets COX-2 to inhibit carcinogenesis. Mol Carcinog. 2008;47:797-805.

165. Hawley SA, Fullerton MD, Ross FA, Schertzer JD, Chevtzoff C, Walker KJ, et al. The ancient drug salicylate directly activates AMP-activated protein kinase. Science. 2012;336:918-22.

166. Ong G, Davis TM, Davis WA. Aspirin is associated with reduced cardiovascular and all-cause mortality in type 2 diabetes in a primary prevention setting: The Fremantle Diabetes study. Diabetes Care. 2010;33:317-21.

167. Pasche B, Wang M, Pennison M, Jimenez H. Prevention and treatment of cancer with aspirin: where do we stand? Semin Oncol. 2014;41:397-401. 
168. Thorat MA, Cuzick J. Role of aspirin in cancer prevention. Curr Oncol Rep. 2013;15:533-40.

169. ASPREE Investigator Group. Study design of Aspirin in Reducing Events in the Elderly (ASPREE): a randomized, controlled trial. Contemp Clin Trials. 2013;36:555-64.

170. Kelly GS. Rhodiola rosea: a possible plant adaptogen. Altern Med Rev. 2001;6:293-302.

171. Schriner SE, Abrahamyan A, Avanessian A, Bussel I, Maler S, Gazarian M, et al. Decreased mitochondrial superoxide levels and enhanced protection against paraquat in Drosophila melanogaster supplemented with Rhodiola rosea. Free Radic Res. 2009;43:836-43.

172. Wiegant FA, Surinova S, Ytsma E, Langelaar-Makkinje M, Wikman G, Post JA. Plant adaptogens increase lifespan and stress resistance in C. elegans. Biogerontology. 2009;10:27-42.

173. Liu Z, Li X, Simoneau AR, Jafari M, Zi X. Rhodiola rosea extracts and salidroside decrease the growth of bladder cancer cell lines via inhibition of the mTOR pathway and induction of autophagy. Mol Carcinog. 2012;51:257-67. This study describes that Rhodila rosea, a novel plant adaptogen, has both anti-aging and anticancer properties via inhibition of the mTOR pathway.

174. Liu Z, Li X, Liu S, Xu X, Tian X, Simoneau AR, et al. Rhodiola rosea L. extract, SHR-5, and metformin exhibit potent activity against bladder carcinogenesis in the UPII-mutant Ha-ras transgenic model. Cancer Res. 2012;72(8 Supplement):618.

175. Bocharova OA, Matveev BP, Baryshnikov AI, Figurin KM, Serebriakova RV, Bodrova NB. The effect of a Rhodiola rosea extract on the incidence of recurrences of a superficial bladder cancer. Urol Nefrol (Mosk). 1995;2:46-7.

176. Li X, Erden O, Li L, Ye Q, Wilson A, Du W. Binding to WGR domain by salidroside activates PARP1 and protects hematopoietic stem cells from oxidative stress. Antioxid Redox Signal. 2014;20:1853-65.

177. Sun C, Wang Z, Zheng Q, Zhang H. Salidroside inhibits migration and invasion of human fibrosarcoma HT1080 cells. Phytomedicine. 2012;19:355-63.

178. Zhang Y, Yao Y, Wang H, Guo Y, Zhang H, Chen L. Effects of salidroside on glioma formation and growth inhibition together with improvement of tumor microenvironment. Chin J Cancer Res. 2013;25:520-6.

179. Loo WT, Jin LJ, Chow LW, Cheung MN, Wang M. Rhodiola algida improves chemotherapy-induced oral mucositis in breast cancer patients. Expert Opin Investig Drugs. 2010;19 Suppl 1: S91-100.

180. Goldberg AA, Richard VR, Kyryakov P, Bourque SD, Beach A, Burstein MT, et al. Chemical genetic screen identifies lithocholic acid as an anti-aging compound that extends yeast chronological life span in a TOR-independent manner, by modulating housekeeping longevity assurance processes. Aging. 2010;2:393-414.
181. Burstein MT, Titorenko VI. A mitochondrially targeted compound delays aging in yeast through a mechanism linking mitochondrial membrane lipid metabolism to mitochondrial redox biology. Redox Biol. 2014;2:305-7. This article revealed a novel mechanism for delaying aging in yeast by lithocholic bile acid. It shows that lithocholic bile acid interacts with mitochondrial membranes to remodel mitochondrial phospholipid dynamics and change redox process.

182. Katona BW, Cummins CL, Ferguson AD, Li T, Schmidt DR, Mangelsdorf DJ, et al. Synthesis, characterization, and receptor interaction profiles of enantiomeric bile acids. J Med Chem. 2007;50:6048-58.

183. Goldberg AA, Titorenko VI, Beach A, Sanderson JT. Bile acids induce apoptosis selectively in androgen-dependent and independent prostate cancer cells. Peer J. 2013;1:e122.

184. Yu MK, Lee DY, Kim YS, Park K, Park SA, Son DH, et al. Antiangiogenic and apoptotic properties of a novel amphiphilic folate-heparin-lithocholate derivative having cellular internality for cancer therapy. Pharm Res. 2007;24:705-14.

185. Kozoni V, Tsioulias G, Shiff S, Rigas B. The effect of lithocholic acid on proliferation and apoptosis during the early stages of colon carcinogenesis: differential effect on apoptosis in the presence of a colon carcinogen. Carcinogenesis. 2000;21:999-1005.

186. [No authors listed] L-theanine. Monograph. Altern Med Rev. 2005; 10: 136-8.

187. Zarse K, Jabin S, Ristow ML. Theanine extends lifespan of adult Caenorhabditis elegans. Eur J Nutr. 2012;51:765-8.

188. Zhang G, Ye X, Ji D, Zhang H, Sun F, Shang C, et al. Inhibition of lung tumor growth by targeting EGFR/VEGFR-Akt/NF- $\mathrm{kB}$ pathways with novel theanine derivatives. Oncotarget. 2014;5: $8528-43$.

189. Ji D, Wang Y, Zhang H, Chen L, Liu X, Sun F, et al. Suppression of proliferation and migration in highly-metastatic lung cancer cells as well as tumor growth by a new synthesized compound $\mathrm{TBrC}$ and its molecular mechanisms of action. Cytotechnology. 2014;66:899-911.

190. Sugiyama T, Sadzuka Y. Theanine and glutamate transporter inhibitors enhance the antitumor efficacy of chemotherapeutic agents. Biochim Biophys Acta. 2003;1653:47-59.

191. Sugiyama T, Sadzuka Y. Theanine, a specific glutamate derivative in green tea, reduces traverse reactions of doxorubicin by changing the glutathione level. Cancer Lett. 2004;212:177-84.

192. Gorbunova V, Seluanov A, Zhang Z, Gladyshev VN, Vijg J. Comparative genetics of longevity and cancer: insights from long-lived rodents. Nat Rev Genet. 2014;15:531-40.

193. Caruso C, Lio D, Cavallone L, Franceschi C. Aging, longevity, inflammation, and cancer. Ann N Y Acad Sci. 2004;1028:1-13. 